\title{
Socio-psychological characteristics and nonverbal behavior of the psychologist, as components of its professional image in student representations
}

\author{
Anna Korochentseva ${ }^{1}$, Nelli Khachaturyan ${ }^{1, *}$ \\ ${ }^{1}$ Don State Technical University, Gagarina sq. 1, 344000 Rostov-on-Don, Russia
}

\begin{abstract}
Today, both in science and in everyday life, there is an increased interest in the peculiarities of the formation of the image and image of representatives of various professions. Is no exception and the profession of psychologist. The greatest interest in the consideration of such an image are not only the various socio-psychological characteristics that fill it in the views of both ordinary people and students studying in the "psychology" direction, but also visual characteristics of the image: expression, and various components of the external appearance.The study showed that students have a stable understanding of the socio-psychological characteristics, elements of non-verbal behavior and appearance of a practical psychologist. The study provides a comprehensive analysis of the ideas of psychology students about the personal characteristics of a practical psychologist, the level of development of perceptual-communicative capabilities; its non-verbal repertoire in terms of diversity, harmony, differentiation; its sensitivity to the non-verbal behavior of the other; ability to manage their nonverbal repertoire adequately for the purpose and situation of communication. The main elements of non-verbal behavior and the appearance of the appearance characteristic of a practical psychologist in the views of students-psychologists and students of other directions are highlighted, and their comparative analysis is carried out.
\end{abstract}

\section{Introduction}

The current state of psychological science, both in fundamental terms and in the field of applied research, is undoubtedly distinguished by a large number of new, interesting and important approaches and directions for practical application. In recent years, in the mass consciousness, there has been a big, positive leap towards a change in everyday ideas about the possibilities of psychology as a science in general, and about the spectrum of areas of psychological work of practicing psychologists in particular. Effective psychological assistance to the population is an urgent problem of modern social life in Russia. Disclosure of the conditions, ways and means of acquiring a positive image by people accompanying a persons mental life meets the need to include the results of such studies in the process of

\footnotetext{
*Corresponding author: nellja-nik@mail.ru
} 
training psychologists. In this connection, the consideration of the image of a practical psychologist in the ideas of students studying psychology also plays an important role.

Combination of socio-psychological characteristics, elements of appearance and expression is a unified image of a practical psychologist, available in the ideas of the people under investigation $[4,5]$. The compliance of a psychologist engaged in counseling practice with such ideas allows to form trusting relationships and increase the effectiveness of the psychotherapeutic process as a whole $[8,9]$. It is also necessary to remember that non-verbal communication is often more informative than the process of verbal interaction, and in this regard, the importance of studying those non-verbal "codes" that the psychologist transmits in the process of practical work with a client increases [9]. Based on the research of A.A. Bodalev, V.A.Labunskaya and others, we consider expression and appearance as a way of cognizing the psychologists inner world on the one hand [5], and a way of translating certain states, relationships, individual characteristics from another $[5,10]$.

Foreign researchers, as well as domestic ones, pay attention to the important role of the visual image of a person in the formation of other people's ideas about it [18]. It is noted that the attitude to one's appearance is an important psychological category that affects the formation of the image, and depends on many factors. Positive self-image is important [12, 13]. Therapeutic ways of influencing the formation of a positive self-image are considered [14]. It is noted that dissatisfaction with their appearance is the main source of experiences for women of all ages and can ultimately negatively affect the image they create [15]. The relationship between self-esteem and dissatisfaction with their appearance was revealed, with women showing greater concern about it [17].

There are studies that highlight various criteria for evaluating a visual image, such as concern with bodily characteristics, the degree of satisfaction with appearance, and the ability to manage impressions using an external image [16].

Clothing plays an important role both in presenting yourself and in presenting your image to others. Women feel differently depending on the size of their clothes, and this affects the impression they make [19].

In Russian psychology, the image of a practical psychologist was studied in the work of E.A. Bykova, she noted that being freshmen, students emphasize mainly communicative features as significant for the successful work of a psychologist, while getting older the importance of volitional personality traits, such as self-confidence, energy, solvency, is emphasized. When assessing the dominant personality traits of an ideal psychologist, priority is given to the qualities of the emotional and moral sphere [2]. The studies also note that the success of the professional activity of the psychologist is ensured by well-developed abilities (general psychological, communicative, verbal, oratory, the ability to self-control), expressed inclinations, interests (interest and respect for another person, a tendency to empathy, curiosity and learning, creativity ), and personal qualities (a high degree of personal responsibility; tolerance, initiative, striving for self-knowledge, originality, resourcefulness, versatility of interests, purposefulness, intuition, etc.) [7].

O.O. Eliseeva studied the image of a psychologist in modern Russia and, on the basis of this, identified the problem of forming and managing the image of a psychologist as a factor in building trust in the process of psychological counseling. She notes that the external appearance is an important component of the image of a psychologist and his professional image, which affects the assessment of personal and professional qualities, that is, it actualizes stereotypical judgments about his professionalism. Some Western studies say that the external appearance of a psychologist actualizes the client's stereotypes regarding his professionalism in the process of psychological counseling $[3,8]$.

Visual-semiotic manifestations of external appearance, according to E.A. Petrova, are an important component of professional communication. Its socio-psychological interpretation significantly affects the formation of the image of any specialist $[6,11]$. V.L. Bozadzhiev, 
speaking about the design of the external appearance of a practical psychologist, notes that his clothes should not attract too much attention, it should help the psychologist, and not suppress him. Women as practice psychologists should dress more conservatively than women who give lecturers. For example, when communicating with a client, it is undesirable to wear clothes with short sleeves, since short sleeves indicate informality $[1,21]$.

Summarizing the theoretical analysis of this problem, it is worth noting that, despite the undoubted interest in the image of a psychologist as a professional, ideas about the image of a practical psychologist of future professionals who are at the stage of mastering this profession remain poorly studied. The ideas of psychology students about the visual image of representatives of the future profession also remain poorly studied. At the same time, it is necessary to pay attention to the fact that depending on who is the subject of ideas, the image of a psychologist as a subject of professional activity can be filled with different characteristics. For example, these differences can be observed in the views of students of psychology and young people who are not related to psychology.

\section{Materials and methods of the research}

On the basis of theoretical assumptions, we formulated the purpose of the research - to study the image of a practical psychologist in the ideas of students studying psychology. The hypothesis of the research was the assumption that the visual image of a practical psychologist in students' ideas will include personality characteristics, as well as elements of non-verbal behavior and external appearance that differ among psychology students and students who are not related to psychology.

To determine the ideas of psychology students and students of other specialities, who are not related to psychology, about the social and psychological characteristics of a practical psychologist, the following methods were used: Semantic differential "Social and psychological characteristics of the personality" (V.A. Labunskaya) [5], as well as descriptions of personal characteristics from the methodology "Diagnostics of interpersonal relations" (T. Leary) [12]. 2. To determine the ideas of students about the non-verbal repertoire of a practical psychologist, the following methodology was used: "Expert assessment of non-verbal communication" (E.V. Kuznetsova) [12]. To determine the subjective ideas about the external appearance of a practical psychologist, the questionnaire "Subjective assessment of the external appearance" was used, which we developed on the basis of the questionnaire of V.A. Labunskaya "Non-verbal characteristics of communication". The characteristics of the face and appearance were added to the characteristics of non-verbal behavior [5].

Empirical object of the research: students, total: 80 people, 40 of them are psychology students, 40 are students of other areas. The reliability of the data obtained was ensured by determining the significance of the differences using the Student's t-test and the quartile procedure using the SPSS computer program.

\section{Results}

At the first stage of the research, we used the following methods: "Diagnostics of interpersonal relations" and the semantic differential "Socio-psychological characteristics of a personality". The task of the subjects was to choose from this list those characteristics that, in their opinion, are endowed with a practical psychologist.

First, we analyzed ideas about the prevailing qualities of a practical psychologist related to the scales: "authoritarian", "selfish", "aggressive", "suspicious", "subordinate", "dependent", "friendly", "altruistic" among students of psychology (1 group). To do this, we 
determined the average values of the severity of indicators for each of the studied scales, on the basis of which, for greater clarity, we presented the data in Table 1.

Table 1. Indicators of the severity of qualities on the scales of a practical psychologist in the perceptions of psychology students and their average values.

\begin{tabular}{|c|c|c|c|c|}
\hline \multirow[t]{2}{*}{ Scale } & \multicolumn{2}{|c|}{ Psychology students' images } & \multicolumn{2}{|c|}{$\begin{array}{c}\text { Images of those not related to } \\
\text { psychology }\end{array}$} \\
\hline & Index & Severity level & Index & Severity level \\
\hline Authoritarian & 8.25 & High & 5.00 & Moderate \\
\hline Selfish & 5.05 & Moderate & 3.90 & Low \\
\hline Aggressive & 3.90 & Low & 3.55 & Low \\
\hline Suspicious & 1.50 & Low & 1.90 & Low \\
\hline Subordinate & 2.55 & Low & 2.15 & Low \\
\hline Dependent & 2.05 & Low & 2.85 & Low \\
\hline Friendly & 4.30 & Low & 6.05 & Moderate \\
\hline Altruistic & 5.25 & Moderate & 5.80 & Moderate \\
\hline
\end{tabular}

Further, to identify the significance of differences in the ideas of psychology students and students of other specialities about the predominant qualities of a practical psychologist, a mathematical procedure such as the Student - T test was used. When comparing the groups, significant differences were revealed:

The "Authoritarian" scale $(\mathrm{t}=4.025)$. This suggests that psychology students endow the image of a practical psychologist with more authoritarian qualities, characteristic to a strong, successful, domineering personality; a self-confident person, in contrast to the ideas of students of other specialities. The "Selfish" scale $(\mathrm{t}=2.407)$. According to the ideas of psychology students, a practical psychologist has more pronounced qualities on this scale, they represent him as a more narcissistic, independent person with a sense of dignity, who loves to compete. Students of other specialities believe that the practical psychologist is less selfish, more inclined to focus on others than on himself. According to the "Dependent" scale $(t=-2.617)$, according to students not related to psychology, a practical psychologist is softer, more trusting, polite, obedient. The "Friendly" scale $(\mathrm{t}=-3.461)$. According to the ideas of students of other specialities, a practical psychologist has more pronounced qualities on this scale, he is inclined to cooperation, flexible and compromise in solving problems and in conflict situations, conformal.

No significant differences were found on other scales. These scales include: "Aggressive" scale $(t=0.621)$. Both groups noted a low level of this quality "Suspicious" scale $(\mathrm{t}=-0.857)$. The presence of the qualities of criticality in relation to others, lack of communication, difficulty in contacts due to self-doubt, isolation, and secrecy should not be expressed in a practical psychologist. "Subordinate" scale $(\mathrm{t}=1.210)$. As students imagine, a practical psychologist should not be in a subordinate position. "Altruistic" scale $(\mathrm{t}=-, 967)$. According to students, a practical psychologist is moderately responsible in relation to other people, delicate, responsive.

Further, using the quartilization procedure, we identified those qualities of a practical psychologist that were selected by more than $75 \%$ of students. Both psychology students and students of other specialities noted the following qualities as characteristic of a practical psychologist: respectful, capable of cooperation, mutual assistance, delicate, self-confident, striving for success.

Among the qualities that were not selected by students of other specialities, but were noted by $75 \%$ of the subjects in the group of psychology students as necessary for a practical psychologist: he has a sense of dignity, strict but fair, can be sincere, is able to be critical of himself, is respected by others, he gives the impression of a significant person, generous, tolerant of shortcomings. Qualities that were not selected by psychology students, but were 
noted by $75 \%$ of the subjects in the group of students of other specialities, as necessary for a practical psychologist: friendly, benevolent, responsive to calls for help, always kind.

After that, in addition, we used the method of semantic differential "Social and psychological characteristics of a personality"; by V.A. Labunskaya. We investigated the socio-psychological characteristics that we identified by psychology students and students of other specialities as necessary in the activities of a practical psychologist. For the analysis of the obtained data, we used the quartilization procedure. We selected those characteristics that were chosen by more than $75 \%$ of the subjects. We found that both groups of students attribute the following qualities to a practical psychologist: quick-witted, realistic, calm, confident, pleasant, tidy. Thus, in both groups, only positive qualities were noted, which speak of professional competence, intellectual development, attractiveness, and disposition to oneself. We have also identified differences. $75 \%$ of psychology students emphasize such qualities as: good-natured, responsible, self-reliant, socially experienced, and students of other specialities identify the following: quick-witted, restrained. For clarity, we present all the qualities in Figure 1.
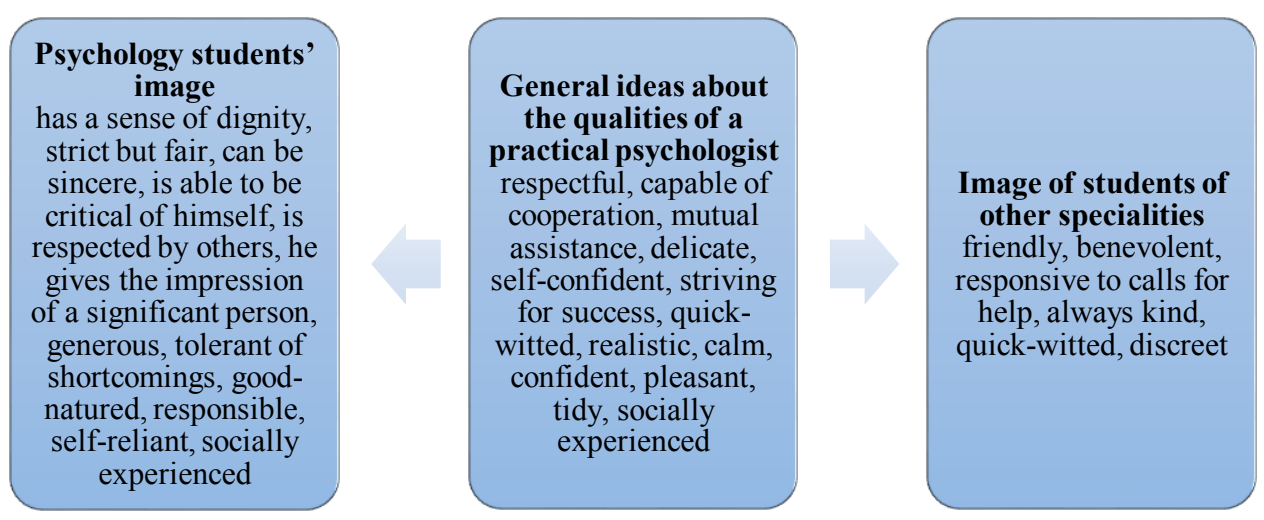

Fig. 1. Representations of psychology students and students of other specialities about the social and psychological qualities of a practical psychologist.

At the second stage of the research the subjects were asked to describe a practical psychologist using the "Expert assessment of non-verbal communication" methodology. This technique allowed us to determine the students' ideas about: the level of development of perceptual and communicative capabilities of a practical psychologist; his non-verbal repertoire in terms of diversity, harmony, differentiation; his sensitivity to the non-verbal behavior of other people and the ability to adequately identify; the ability to manage his nonverbal repertoire adequate to the purpose and situation of communication. 


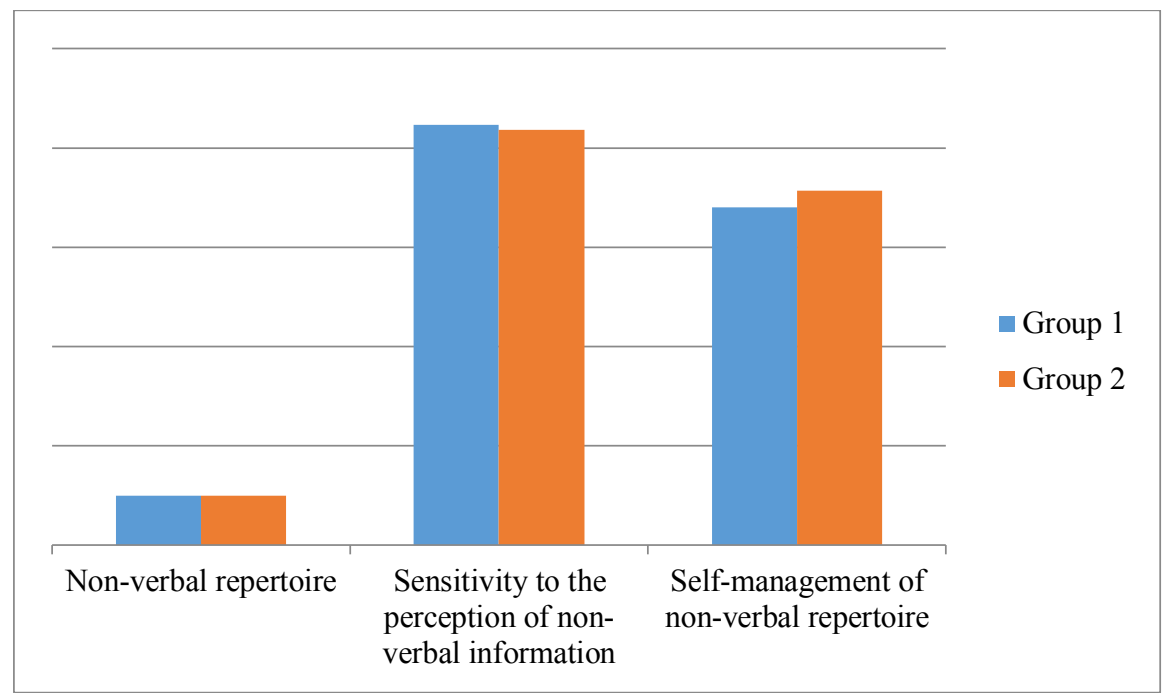

Fig. 2. The severity of the non-verbal repertoire, sensitivity to the perception of non-verbal information and self-management of the non-verbal repertoire in a practical psychologist in the views of groups 1 and 2 .

A comparative analysis of the ideas of psychology students (group 1) and students of other specialities (group 2) did not show significant differences. Both groups marked high scores on the scale "Sensitivity to the perception of non-verbal information" $(\mathrm{m}=21.15 ; \mathrm{m}$ $=20.90)$ and "Self-management of non-verbal repertoire" $(\mathrm{m}=17.00 ; \mathrm{m}=17.85)$. This suggests that in the ideas of both groups, a practical psychologist easily understands the emotions of other people by the expression on their faces, is able to determine their state of health by a change in gait, posture, and also controls well their non-verbal repertoire.

After that, using the method "Subjective assessment of external appearance", we investigated the elements of non-verbal behavior and external appearance, which make up the visual image of a practical psychologist.

For the analysis of the obtained data, we used the quartilization procedure. In the image of a practical psychologist, we selected those characteristics that were selected by more than 70 percent of the subjects. The data obtained are shown in Figure 3.

Among the characteristics chosen were those that were the same for both groups and those that were different. Characteristics, which were noted as important for a practical psychologist by students-psychologists, but not chosen by students of other specialities: 1 . Non-verbal behavior: poses are harmonious, synchronous, identical to those of a partner; 2 . Facial characteristics: honest, decisive, kind, smug. 

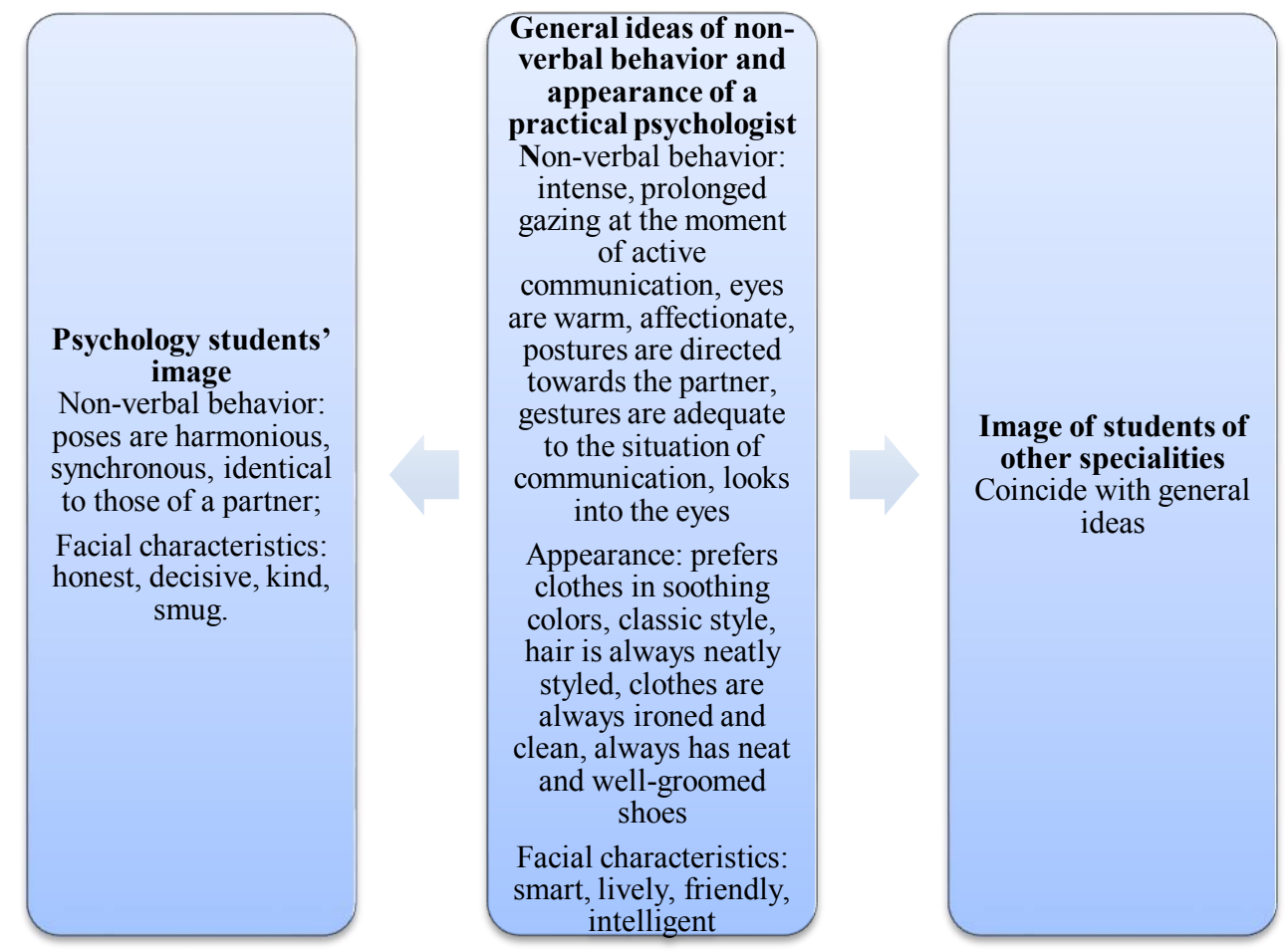

Fig. 3. Image of non-verbal behavior and the external appearance of a practical psychologist according to psychology students and students of other specialities.

The characteristics that were not selected by any of the studied groups reflect: a) lack of eye contact, coldness and cruelty of the gaze, this suggests that the gaze of a practical psychologist plays a very important role in communication with people; b) the disharmony of the poses, the direction from the partner, the sharpness of the gestures testifies to the importance of the non-verbal behavior of a practical psychologist, since with the help of it you can express your attitude towards the partner of communication.

\section{Discussion}

A consciously formed image of a psychologist increases the quality of his professional activity both meaningfully - through social roles and positions, the level of which is achieved by the subject - and "in tempo-correcting terms".

On the basis of theoretical and empirical analysis, we found out that the external appearance, non-verbal behavior and socio-psychological characteristics are important components of the image of a psychologist and his professional image, affecting the assessment of personal and professional qualities.

The external appearance of a practical psychologist creates certain attitudes of the client in the process of psychological counseling. Thus, we can talk about the existence of various stereotypical ideas about the internal and external qualities of a psychologist, as well as about his different image and professional image.

A psychologist's orientation to the expectations of clients from a particular image can increase the efficiency of his activities, correctly form the "first impression", and establish trusting relationships. 
As a result of our research, we identified ideas about the important components of the image of a practical psychologist. Among them are socio-psychological and personal characteristics, non-verbal communication and appearance. And on this basis, we can give the following recommendations:

A practical psychologist should develop and actively demonstrate such qualities as: energy, competence, success in business, responsibility, responsiveness, adherence to the rules and principles of a "good taste", initiative, the desire to help, the manifestation of warmth and friendliness in relationships, focus on people, ingenuity, confidence, social experience, restraint.

To form a trusting relationship, a practical psychologist needs to exhibit non-verbal behavior aimed at a communication partner and demonstrate active, attentive behavior. This can manifest itself in intense, prolonged gazing at the moment of active communication, warm, affectionate eyes, poses directed to the partner, gestures adequate to the situation of communication. One should not demonstrate poses directed from the partner, sharp gestures, lack of eye contact, coldness and cruelty of the gaze.

In the external appearance, a practical psychologist should adhere to the following recommendations: clothing of calm tones, classic style, clothes should be ironed and clean, the hairstyle is always neatly styled, neat and well-groomed shoes.

\section{Conclusions}

Thus, as a result of the research, the ideas about the image of a practical psychologist of psychology students, we made the following conclusions:

In the students' perceptions, the image of a practical psychologist is endowed with certain socio-psychological characteristics. In the minds of psychology students, these are qualities such as: energetic, competent, successful in business, responsible, responsive, striving to be in agreement with the opinions of others, has a sense of dignity, strict but fair, maybe sincere, capable of being critical of oneself, respected by others, gives the impression of a significant person, generous, tolerant of shortcomings, good-natured, responsible, self-reliant, socially experienced. According to the ideas of young people who are not related to psychology, this image is endowed with such qualities as: follows the conventions, rules and principles of the "good taste", proactive, enthusiastic, has a desire to help, manifests warmth and friendliness in relationships, people-oriented, friendly, benevolent, responsive to calls for help, always kind, quick-witted, restrained.

Significant differences were found in the socio-psychological characteristics included in the ideas about the image of a practical psychologist among psychology students and young people who are not related to psychology. Characteristics related to the scales: selfish, authoritarian, independent, friendly, are assessed significantly higher in the perceptions of psychology students. Psychology students present a practical psychologist as more narcissistic, dignified, and competitive. In the ideas of students of other specialities, the most pronounced characteristics were: trusting, polite, obedient, compromising, inclined to orientate themselves towards others. This suggests that students of other specialities endow the image of a practical psychologist with such characteristics as: tend to sacrifice their own interests, to yield and bend in conflict situations.

There is a set of certain socio-psychological characteristics that are included in the ideas about the image of a practical psychologist, both among psychology students and students of other specialities. These are such characteristics as: respectful, capable of cooperation, mutual assistance, delicate, self-confident, striving for success, quick-witted, realistic, calm, confident, pleasant, neat, responsible, socially experienced, reserved.

Both in the ideas of psychology students and in the ideas of young people who have nothing to do with psychology, the non-verbal repertoire of a practical psychologist in terms 
of its diversity, harmony and differentiation is characterized by the ability to complement well the content of words with non-verbal means (facial expressions, gestures, posture). Nonverbal behavior corresponds to what he is talking about, by expressive behavior it is easy to understand what the psychologist feels about others.

Both in the ideas of psychology students and in the ideas of other students, the sensitivity to the perception of non-verbal information has a high indicator. This indicates that in the ideas of both groups of students, a practical psychologist easily understands the emotions of other people by the expression of their faces, understands the meaning of views (the manifestation of interest, sympathy, excitement, etc.), is able to determine the well-being of other people by a change in gait, posture.

In the ideas of psychology students, as well as in the ideas of students of other specialities, a practical psychologist is characterized by a high level of control over his non-verbal repertoire. His non-verbal repertoire is adequate to the goals and situations of communication and has a high score.

Both psychology students and students of other specialities noted the following characteristics of non-verbal behavior, the design of the external appearance and face, as necessary components of the image of a practical psychologist: non-verbal behaviorintensive, prolonged gazing at the moment of active communication, eyes are warm, affectionate, postures are directed towards the partner, gestures are adequate to the situation of communication, looks into the eyes. He/she prefers clothes of calm tones, classic style of dress, hair is always neatly styled, clothes are always ironed and clean, always has neat and well-groomed shoes. The face is described as smart, lively, intelligent, affable.

Differences were found in perceptions of non-verbal characteristics. The characteristics of non-verbal behavior, the design of the external appearance and the face that entered the image of a practical psychologist were: harmonious, synchronous postures, identical to those of a partner; an honest, decisive, kind, self-satisfied face. The characteristics that were not selected by any of the studied groups were: lack of eye contact, coldness and cruelty of the gaze, this suggests that the gaze of a practical psychologist plays a very important role in communication with people; disharmony of poses, direction from the partner, sharpness of gestures, which indicates the importance of the psychologist's non-verbal behavior, since with the help of it you can express your attitude towards the partner of communication.

\section{References}

1. V.L. Bozadzhiev, Psychologist: profession and personality (Printing House, Chelyabinsk, 2011) https://www.koob.ru/bozadzhiev

2. E. Bykova, Concept 12 (2015) https://www.elibrary.ru/contents.asp?id=36359915

3. O.O. Eliseeva, Bulletin of PSTGU IV: Pedagogy. Psychology 2(21), 103-113 (2011) https://cyberleninka.ru/article/n/obraz-psihologa-v-sovremennoy-rossii

4. A.V. Korochentseva, V.A. Terekhin, Russian psychological journal 13(1), 1812-1853 (2016) https://cyberleninka.ru/article/n/osobennosti-formirovaniya-vizualnogo-obrazarukovoditelya-na-osnove-razlichnyh-komponentov-ego-vneshnego-oblika-ineverbalnogo

5. V.A. Labunskaya, Human Expression: Communication and Interpersonal Cognition (Phoenix, Rostov-on-Don, 1999) https://cyberleninka.ru/article/n/ekspressiyacheloveka-i-ee-izuchenie-v-kontekste-gumanitarnoy-sotsialnoy-psihologii

6. E.A. Petrova, Visual psychosemiotics of communication (Academy of Imageology, Moscow, 2015) https://www.elibrary.ru/item.asp?id=23406459 
7. N.V. Kilinskaya, Psychological sciences: theory and practice: materials of the I International. scientific. conf. (Buki-Vedi, Moscow, 2012) https://moluch.ru/conf/psy/archive/33/1922/

8. R. Barrow, College Student Journal 34(1), $123 \quad$ (2016) https://www.questia.com/library/journal/1G1-62839409/determining-stereotypicalimages-of-psychologists

9. P.A. Horas, C. Morales de Barbenza, E.B. De Mikusinski, O.A. Montoya, J. Castillo de Pantano, Acta Psiquiatrica y Psicologica de America Latina 23/2, 118 - 130 (1977) https://journals.indexcopernicus.com/search/details?id=52759

10. M.L. Knapp, J.A. Hall, Nonverbal Communication in Human Interaction (Thomson Learning, Crawfordsville, IN, 2002) https://b-ok.cc/book/2565928/8e018e

11. B.M. DePaulo, Psychological Bulletin 111(2), 203-243 https://www.elibrary.ru/item.asp?id=318154

12. N.P. Fetiskin, V.V. Kozlov, G.M. Manuilov, Social and psychological diagnostics of personality development and small groups (Publishing house Of the Institute of Psychotherapy, Moscow, 2009) https://www.elibrary.ru/item.asp?id=20100884\&

13. E. Guest, B. Costa, H. Williamson, J. Meyrick, E. Halliwell, D. Harcourt, Body Image 30, 10-25 (2019) doi: 10.1016/j.bodyim.2019.04.002

14. Z. Ahmadi, Z. Abbaspoor, N. Behroozy, A.S. Malehi, Iranian Red Crescent Medical Journal 19(10), e14903 (2017) doi: 10.5812/ircmj.14903

15. E.R. Albertson, K.D. Neff, K.E. Dill-Shackleford, Mindfulness 6(3), 444-454 (2015) doi: 10.1007/s12671-014-0277-3

16. L. Avalos, T.L. Tylka, N. Wood-Barcalow, Body Image 2(3), 285-297 (2005) doi: 10.1016/j.bodyim.2005.06.002

17. T.A. Brown, T.F. Cash, P.J. Mikulka, Journal of Personality Assessment 55(1-2), 135 144 (1990) doi: 10.1080/00223891.1990.9674053

18. A. Buchholz, H. Mack, G. McVey, S. Feder, N. Barrowman, Eating Disorders 16(4), 308-321 (2008) doi: 10.1080/10640260802115910

19. J.R. Grossbard, C.M. Lee, C. Neighbors, M.E. Larimer, Sex Roles 60(3-4), 198207 (2009) doi: 10.1007/s11199-008-9535-y

20. G. Vassiliou, V. Vassiliou, International Journal of Social Psychiatry 13(3), 224-228 (1967) doi: 10.1177/002076406701300307

21. V.L. Bozadzhiev, European Journal of Natural History 3, 135-136 (2008) https://elibrary.ru/item.asp?id=18832396

22. J.M. Alleva, K. Holmqvist Gattario, C. Martijn, C. Lunde, Body Image 6(31), 71-80 (2019) doi: 10.1016/j.bodyim.2019.08.008 